\title{
Dietary fat intake in healthy adolescents: inverse relationships between the estimated intake of saturated fatty acids and serum cholesterol
}

\author{
Gösta Samuelson, Lars-Erik Bratteby, Rawya Mohsen and Bengt Vessby* \\ Units of Clinical Physiology and Clinical Nutrition Research, University of Uppsala, Uppsala, Sweden
}

(Received 17 April 2000 - Revised 5 September 2000 - Accepted 20 October 2000)

\begin{abstract}
The objective of the present study was to describe the intake of dietary fatty acids among healthy 15-year-old boys and girls and to relate the intake of specific fatty acids and the fatty acid composition of the serum cholesterol esters to serum lipid, apolipoprotein (Apo) and insulin concentrations respectively. Fifty-two girls and forty-two boys were randomly selected from the official population register. Unexpectedly, significant inverse associations were found between the dietary content of saturated fatty acids with a chain length of four to fifteen $\mathrm{C}$ atoms, mainly derived from milk fat, as well as the corresponding fatty acids in the serum cholesterol esters, on the one hand and the serum concentrations of cholesterol and ApoB on the other. The estimated dietary intake of 4:0-10:0, 12:0 and 14:0 respectively, were all significantly inversely related to the serum cholesterol $(r-0.32, r-0.31, r-0 \cdot 30$, all $P<0.05)$ and ApoB $(r-0.42, r-0.42$, and $r-0.40$, all $P<0.05)$ concentrations in girls and 12:0 to the ApoB concentration $(r-0.55$, $P<0.01)$ in boys. The proportions of 12:0 and 15:0 in the serum cholesterol esters were negatively correlated with the serum cholesterol concentrations in both girls $(r-0 \cdot 34, r-0 \cdot 32$, $P<0.05)$ and boys $(r-0.53, P<0.01 ; r-0.32, P<0.05)$ and with the ApoB concentrations among boys $(r-0.61, P<0.01 ; r-0.43, P<0.05)$. It is conceivable that milk fat contains or is associated with some component in the diet, or some other characteristics of the food intake, which counterbalances the expected positive relationships between saturated fat intake and lipid levels.
\end{abstract}

Milk fat: Fatty acid composition: Serum lipids

Lifestyle factors, especially food habits, smoking and degree of physical activity are, in addition to genetic disposition, important determinants of health and disease. The food habits are probably to some extent established already in childhood and adolescence. Recently, two epidemiological studies have been conducted in Sweden aimed at establishing food habits and nutrient intake in adolescents (Bergström et al. 1993; Samuelson et al. 1996). By analysing the fatty acid composition in serum (Glatz et al. 1989; Ma et al. 1995; Nikkari et al. 1995) or adipose tissue (Field et al. 1985; van Staveren et al. 1986), it is possible to get additional information about the dietary fat quality, especially with regard to the intake of essential fatty acids.

The aim of the present study was to describe the intake of dietary fat among a group of randomly selected 15-yearold boys and girls and to relate the intake of specific fatty acids, and the fatty acid composition of the serum lipid esters to serum lipid, apolipoprotein (Apo) and insulin concentrations respectively, and also to the food sources from which the dietary fatty acids were derived. The intention was to investigate whether the existing dietary fat intake in this age group could be shown to be related to metabolic variables which have been indicated as risk factors for the development of CHD in adult populations.

\section{Material and methods}

The study was undertaken in the town of Trollhättan, Sweden, an industrial town with about 55000 inhabitants. The study region and the population have been described in detail elsewhere (Samuelson et al. 1996).

From the official population register 259 healthy 15year-old boys and girls were drawn at random. From this group, fifty-seven adolescents were excluded because they were not interested in taking part in the extensive longitudinal study. Thus, 202 adolescents took part in the nutritional survey. When the participants and the nonparticipants of the randomized sample were compared, no significant differences in the mean weights and heights 
either at birth or at the age of 15 years were found. In addition there were no differences in their socio-economic background, except regarding their mothers' education, which was higher in the study group $(P<0.05)$. In all other comparable aspects the participants and the nonparticipants were similar (Samuelson et al. 1996). The adolescents were all healthy at the time for medical examination and blood sampling. A subgroup of ninetythree adolescents, fifty-one girls and forty-two boys, were randomly selected for the present study. The anthropometric and clinical characteristics of this subgroup are very similar to those earlier described for the total group (Samuelson et al. 1996) indicating that the subsample studied here is representative of the whole group of participants. Some of the laboratory analyses could not be performed in all ninety-three subjects due to lack of sufficient amount of remaining serum. There was no systematic selection but the number of analyses performed in a subject was solely determined by the amount of serum available with the priority order: fatty acid composition, serum lipids, serum insulin, serum Apo. While serum fatty acids and lipid concentrations were analysed in virtually all, serum ApoA-I and ApoB could only be analysed in forty-nine (twenty-seven girls and twenty-seven boys) and fifty (twenty-eight girls, twenty-two boys) individuals respectively. There was no indication that these subjects differed from the others with regard to dietary habits or clinical characteristics.

The study was approved by the Ethic Research Committee of the Medical Faculties of the Universities of Uppsala and Gothenburg.

All the subjects were clinically examined by two paediatricians. Height was measured by a standardised wall measuring-stick and weight by a digital scale when the participants were only wearing light underwear.

\section{Dietary assessment}

One dietitian gave detailed instructions on how to record all food items eaten during one week, i.e. a $7 \mathrm{~d}$ record (Bingham, 1987). In their home the adolescents weighed their food using electronic scales (Soenhle, Mohardt, Germany), while for all other meals and between-meal eating and food eaten outside the home, food models were used as aids in determining the amounts consumed (Håglin et al. 1995). When the $7 \mathrm{~d}$ dietary record was validated by the doubly-labelled water method in a randomized subsample of fifty adolescents who participated in the present study (Bratteby et al. 1998), an underestimation of energy intake by approximately $20 \%$ was found in accordance with reports by others. From the $7 \mathrm{~d}$ dietary records energy and nutrients were computed using the food database of the Swedish National Food Administration (report no. 14, Pc version, 1992; Uppsala, Sweden) which includes 1593 foods and dishes.

\section{Physical activity}

An activity diary was used to assess the total energy expenditure during the same $7 \mathrm{~d}$ as for the dietary recording. The adolescents scored their main daily activity during all 15 min periods of each day and scaled it in one of nine activity levels defined according to its energy cost (Bratteby et al. 1997b). In a validation study in a subgroup of adolescents using the doubly-labelled water method, the activity diary provided close estimates of total energy expenditure on a group basis (Bratteby et al. 1997a).

\section{Blood sampling and chemical analyses}

The blood samples were collected after an overnight fast. After centrifugation the sera were collected and stored at $-70^{\circ} \mathrm{C}$ until analysed. Triacylglycerol and cholesterol concentrations were measured in serum by enzymatic methods, using the IL Test Cholesterol Triander's method 181618-80 and the IL Test Enzymatic-ColorimetricMethod 1811709-00 for use in Monarch apparatus (Instrumentation Laboratory, Lexington, MA, USA). The concentrations of serum ApoB and ApoA-I were determined by immunoturbidimetry in a Monarch apparatus using monospecific polyclonal antibodies against ApoB and ApoA-I (Orion Diagnostic, Espoo, Finland). The samples were preincubated prior to the assay, as suggested by Da Col \& Kostner (1983).

The fatty acid composition of the serum cholesterol esters was determined by GLC as described previously (Boberg et al. 1985). The serum insulin concentrations were measured by an ELISA test from Boehringer Mannheim GmbH (Mannheim, Germany).

\section{Statistical methods}

The results of this investigation were analysed using the software system Statistical Analysis System (SAS Institute Inc., Cary, NC, USA). For comparison of means between boys and girls the unpaired $t$ test was used. Pairwise associations between variables were examined by Pearson product moment correlation analysis when the data were normally distributed. The triacylglycerol and insulin concentrations were logarithmically transformed before analysis by Pearson linear correlation. All other variables were normally distributed. Partial correlations were used when adjusting for BMI and physical activity to see if the relationships were still there after adjustment. Correlations with $P$ values $<0 \cdot 1$ are included in the tables. $P$ values $\leq 0.05$ or less are considered significant.

\section{Results \\ Clinical characteristics}

The mean body weight of the boys was significantly greater than that of the girls while the BMI was identical (Table 1). Three-quarters of the boys and almost all of the girls in the total sample had reached advanced puberty (Tanner stages 4 and 5; Tanner, 1962). The girls had on average higher serum cholesterol, serum ApoA-I and a tendency to higher ApoB concentrations, while there was no difference with regard to the serum triacylglycerols and the serum insulin concentrations. 
Table 1. Clinical characteristics of subjects (Mean values and standard deviations for fifty-one girls and forty-two boys)

\begin{tabular}{|c|c|c|c|c|c|}
\hline & \multicolumn{2}{|c|}{ Girls } & \multicolumn{2}{|c|}{ Boys } & \multirow{2}{*}{$\begin{array}{l}\text { Statistical significance of } \\
\text { difference between boys and girls: } P\end{array}$} \\
\hline & Mean & SD & Mean & SD & \\
\hline Body weight (kg) & $55 \cdot 7$ & $9 \cdot 8$ & $61 \cdot 6$ & 13.7 & 0.021 \\
\hline BMI $\left(\mathrm{kg} / \mathrm{m}^{2}\right)$ & $20 \cdot 3$ & $3 \cdot 0$ & $20 \cdot 4$ & 3.6 & 0.860 \\
\hline Serum triacylglycerol $(\mathrm{mmol} / \mathrm{l})$ & 0.90 & 0.37 & 0.83 & 0.37 & 0.393 \\
\hline Serum cholesterol (mmol/l) & 4.70 & 1.03 & 4.09 & 1.00 & 0.006 \\
\hline Serum insulin (mU/l) & 11.0 & $3 \cdot 6$ & $10 \cdot 8$ & $4 \cdot 3$ & 0.855 \\
\hline Serum ApoA-I (g/l)* & $1 \cdot 30$ & 0.20 & $1 \cdot 13$ & $0 \cdot 13$ & 0.002 \\
\hline Serum ApoB $(g / l) \dagger$ & 0.71 & $0 \cdot 16$ & 0.63 & $0 \cdot 14$ & 0.080 \\
\hline
\end{tabular}

* Girls $n 27$, boys $n 22$.

† Girls $n 28$, boys $n 22$.

\section{Estimated dietary fat intake}

The mean dietary intake and the average intake of dietary fatty acids (\% energy), as calculated from the $7 \mathrm{~d}$ dietary records, are given in Tables 2 and 3. The proportion of energy derived from fat was slightly greater among the boys (NS). The dietary fat quality, as expressed by the relative proportions of the different fatty acids, was similar in boys and girls. The only difference was a slightly higher proportion of linoleic acid among the boys.

\section{Fatty acid composition of the serum cholesterol esters}

The fatty acid composition of the serum cholesterol esters was similar among the boys and the girls (Table 4). However, the boys had on average a somewhat greater proportion of palmitic (16:0) and stearic (18:0) acids while the girls had a greater proportion of palmitoleic $(16: 1 n-7)$ acid in their cholesterol esters. The proportions of linoleic acid were identical in boys and girls.

\section{Relationships between intake of fatty acids and fatty acid composition of the serum cholesterol esters}

The relationships between the estimated proportions of specific fatty acids in the diet and the corresponding fatty

Table 2. Mean daily intake of energy, energy-yielding nutrients and dietary fibre*

(Mean values and standard deviations)

\begin{tabular}{lccccc}
\hline & \multicolumn{2}{c}{ Girls $(n 51)$} & & \multicolumn{2}{c}{ Boys $(n$ 42) } \\
\cline { 2 - 3 } \cline { 6 - 6 } \cline { 5 - 6 } & Mean & SD & & Mean & SD \\
\hline Energy (kJ) & 7318 & 1331 & & 10347 & 2067 \\
Energy (kcal) & 1749 & 389 & & 2473 & 494 \\
Fat (g) & 59 & 18 & & 88 & 18 \\
Fat (\% energy) & 30.4 & $5 \cdot 2$ & & 32.1 & 3.8 \\
Protein (g) & 62 & 14 & & 91 & 22 \\
Protein (\% energy) & 14.2 & $2 \cdot 1$ & & 14.7 & 2.1 \\
Carbohydrates (g) & 239 & 58 & & 327 & 77 \\
Carbohydrates (\% energy) & 54.8 & 5.0 & & 52.8 & 4.4 \\
Alcohol (g) & 0.9 & 3.1 & & 0.5 & 1.6 \\
Alcohol (\% energy) & 0.3 & 1.1 & & 0.1 & 0.4 \\
Cholesterol (mg) & 213 & 79 & & 324 & 103 \\
Fibre (g) & 14.0 & 5.0 & & 18.6 & 5.5 \\
\hline
\end{tabular}

* Nutrient intake measured with a $7 \mathrm{~d}$ weighed record and analysed using the Swedish National Food Administration food database (report no. 14, Pc version, 1992; Uppsala, Sweden). acids in serum were generally in the expected directions, although mostly not significantly so due to the rather small groups of subjects (data not shown).

Serum cholesterol ester fatty acid composition and the concentrations of serum lipids, apolipoproteins and insulin

Although the number of participants was relatively small, there were several significant associations between the proportions of different fatty acids in the serum cholesterol esters on the one hand and the metabolic variables on the other (Table 5, Fig. 1). A general pattern of negative correlations between the proportions of the saturated fatty acids with a chain length of twelve and fifteen $\mathrm{C}$ atoms, and the serum cholesterol, serum ApoB and serum ApoA-I concentrations respectively was found, with a negative correlation between the proportion of 15:0 and ApoB:ApoA-I in boys. In addition, there was a rather strong positive association between the proportion of palmitoleic acid in the cholesterol esters and the ApoB concentration in boys. Significant positive relationships were detected between the proportions of 14:0, 16:1 and 18:3n-6 in cholesterol esters and the serum triacylglycerol concentrations in girls.

While the proportion of linoleic acid was negatively related to the ApoB concentration in boys, there were positive relationships between the long-chain unsaturated $n-6$ fatty acids and serum cholesterol and the serum ApoB concentrations. Among the girls there was a significant positive relationship between the triacylglycerol concentrations and $\gamma$-linolenic acid (18:3n-6), while the dihomo- $\gamma$ linolenic (20:3n-6) and arachidonic (20:4n-6) acids were negatively related to the serum insulin concentrations.

All data given in Table 5 are adjusted by partial correlation for differences in BMI, as are the data presented in Table 6. However, the corresponding relationships were nearly identical before the adjustment for differences in BMI, as well as after adjustment for different degrees of physical activity.

\section{Proportions of fat in the diet and serum lipids, apolipoproteins and insulin}

When the proportions of dietary fatty acids, as estimated from dietary records and adjusted for energy intakes, were related to the metabolic variables (Table 6, Fig. 2), a 
Table 3. Dietary fat intake (\% energy) $)^{\star}$

(Mean values and standard deviations)

\begin{tabular}{|c|c|c|c|c|c|c|c|}
\hline & \multicolumn{2}{|c|}{ All ( $n$ 94) } & \multicolumn{2}{|c|}{ Girls ( $n 51)$} & \multicolumn{2}{|c|}{ Boys (n 42) } & \multirow{2}{*}{$\begin{array}{l}\text { Statistical significance of difference } \\
\text { between boys and girls: } P\end{array}$} \\
\hline & Mean & SD & Mean & SD & Mean & SD & \\
\hline Total fat & $31 \cdot 1$ & 4.7 & $30 \cdot 4$ & $5 \cdot 2$ & $32 \cdot 1$ & 3.8 & 0.083 \\
\hline Saturated & $13 \cdot 8$ & $2 \cdot 4$ & $13 \cdot 6$ & $2 \cdot 6$ & $14 \cdot 1$ & $2 \cdot 2$ & 0.326 \\
\hline Monounsaturated & $10 \cdot 9$ & $2 \cdot 2$ & $10 \cdot 6$ & $2 \cdot 4$ & $11 \cdot 3$ & $1 \cdot 8$ & 0.140 \\
\hline Polyunsaturated & 4.2 & 1.0 & 4.1 & 1.1 & 4.4 & 0.7 & 0.013 \\
\hline $4: 0-10: 0$ & $1 \cdot 2$ & 0.4 & $1 \cdot 2$ & 0.4 & $1 \cdot 2$ & 0.4 & 0.963 \\
\hline $12: 0$ & 0.7 & 0.2 & 0.7 & 0.2 & 0.7 & 0.2 & 0.786 \\
\hline $14: 0$ & 1.5 & 0.4 & 1.5 & 0.4 & 1.5 & 0.3 & 0.736 \\
\hline $16: 0$ & $6 \cdot 7$ & $1 \cdot 1$ & $6 \cdot 6$ & $1 \cdot 2$ & 6.9 & $1 \cdot 0$ & 0.153 \\
\hline $16: 1 n-7$ & 0.6 & 0.2 & 0.6 & 0.2 & 0.6 & 0.2 & 0.145 \\
\hline $18: 0$ & $3 \cdot 1$ & 0.6 & 3.0 & 0.7 & $3 \cdot 2$ & 0.5 & 0.340 \\
\hline $18: 1 n-9$ & $9 \cdot 8$ & $2 \cdot 0$ & $9 \cdot 6$ & $2 \cdot 2$ & $10 \cdot 1$ & $1 \cdot 7$ & $0 \cdot 175$ \\
\hline $18: 2 n-6$ & 3.5 & 0.8 & 3.4 & 0.9 & 3.7 & 0.6 & 0.014 \\
\hline $18: 3 n-3$ & 0.5 & $0 \cdot 1$ & 0.5 & 0.2 & 0.5 & $0 \cdot 1$ & 0.439 \\
\hline $20: 0$ & 0.1 & 0.03 & 0.1 & 0.04 & 0.1 & 0.03 & 0.443 \\
\hline $20: 4 n-6$ & 0.04 & 0.02 & 0.04 & 0.02 & 0.04 & 0.02 & 0.129 \\
\hline $20: 5 n-3$ & 0.01 & 0.01 & 0.01 & 0.01 & 0.01 & 0.01 & $0 \cdot 159$ \\
\hline $22: 5 n-3$ & 0.01 & 0.01 & 0.01 & 0.01 & 0.01 & 0.01 & 0.987 \\
\hline $22: 6 n-3$ & 0.04 & 0.03 & 0.04 & 0.03 & 0.04 & 0.03 & 0.337 \\
\hline
\end{tabular}

* Nutrient intake measured with a 7 d weighed record and analysed using the Swedish National Food Administration food database (report no. 14, Pc version, 1992 Uppsala, Sweden).

picture emerged that in several aspects was similar to that described earlier. Thus, generally negative relationships between the intake of saturated fatty acids and serum lipid levels were found. This was true for the serum triacylglycerol in boys (with similar but not statistically significant associations in girls), the serum cholesterol in girls (with weak correlations in the same direction among the boys) and the serum ApoB concentrations among both sexes. Also, there were negative associations with the serum insulin concentrations in boys. On the other hand, with the exception of a negative relationship between the proportion of arachidonic acid and serum triacylglycerol in girls, all significant correlations between the proportions of longchain $n-6$ and $n-3$ fatty acids and the serum lipid concentrations, were positive in both sexes.

Virtually identical data were achieved when the data for absolute intakes of the different fatty acids were used in the calculations, as well as when no adjustment for BMI was undertaken. Thus, there were also significant negative relationships between the estimated absolute intakes of fatty acids with chain length four to ten, twelve and fourteen, and both serum cholesterol and ApoB in girls and for the intake of 12:0 and ApoB in boys. These associations, as well as the positive relationships between for example the intake of eicosapentaenoic acid and docosahexaehoic acid and serum cholesterol and ApoB were retained, even after adjustment for different degrees of physical activity.

\section{Relationships between intake of different foods and metabolic variables}

The diets were divided into thirty-seven different food groups which were correlated with the metabolic variables. Very few significant associations could be demonstrated. Among the girls there were no significant associations at all

Table 4. Fatty acid composition (\%) of the serum cholesterol esters*

(Mean values and standard deviations)

\begin{tabular}{|c|c|c|c|c|c|c|c|}
\hline \multirow[b]{2}{*}{ Fatty acid } & \multicolumn{2}{|c|}{ All (n 93) } & \multicolumn{2}{|c|}{ Girls ( $n 51)$} & \multicolumn{2}{|c|}{ Boys (n 42) } & \multirow{2}{*}{$\begin{array}{l}\text { Statistical significance of difference } \\
\text { between boys and girls: } P\end{array}$} \\
\hline & Mean & SD & Mean & SD & Mean & SD & \\
\hline $12: 0$ & 0.16 & 0.06 & 0.15 & 0.07 & 0.17 & 0.06 & 0.036 \\
\hline $14: 0$ & 0.99 & 0.19 & 0.97 & 0.20 & 1.01 & 0.19 & 0.380 \\
\hline $15: 0$ & 0.26 & 0.06 & 0.25 & 0.06 & 0.27 & 0.07 & 0.108 \\
\hline 16:0 & $11 \cdot 18$ & 0.68 & 11.01 & 0.66 & 11.41 & 0.66 & 0.004 \\
\hline $16: 1 n-7$ & 3.38 & 0.92 & 3.70 & 1.02 & 2.97 & 0.57 & 0.001 \\
\hline 18:0 & 0.99 & 0.21 & 0.93 & 0.18 & 1.06 & 0.22 & 0.001 \\
\hline $18: 1 n-9$ & $21 \cdot 12$ & $1 \cdot 70$ & 21.03 & $1 \cdot 81$ & $21 \cdot 24$ & 1.57 & 0.560 \\
\hline $18: 2 n-6$ & 51.99 & $2 \cdot 86$ & 51.99 & 3.06 & 51.98 & $2 \cdot 63$ & 0.981 \\
\hline $18: 3 n-6$ & 0.82 & 0.33 & 0.89 & 0.38 & 0.75 & 0.22 & 0.168 \\
\hline $18: 3 n-3$ & 0.93 & 0.22 & 0.94 & 0.23 & 0.91 & 0.22 & 0.441 \\
\hline $20: 3 n-6$ & 0.73 & 0.12 & 0.72 & 0.12 & 0.73 & 0.11 & 0.747 \\
\hline $20: 4 n-6$ & 5.85 & 0.85 & $5 \cdot 82$ & 0.92 & 5.88 & 0.75 & 0.709 \\
\hline $20: 5 n-3$ & 0.95 & 0.34 & 0.94 & 0.32 & 0.97 & 0.37 & 0.620 \\
\hline $22: 6 n-3$ & 0.61 & 0.15 & 0.61 & 0.15 & 0.62 & 0.14 & 0.614 \\
\hline
\end{tabular}

* For details of analytical procedures see p. 334. 

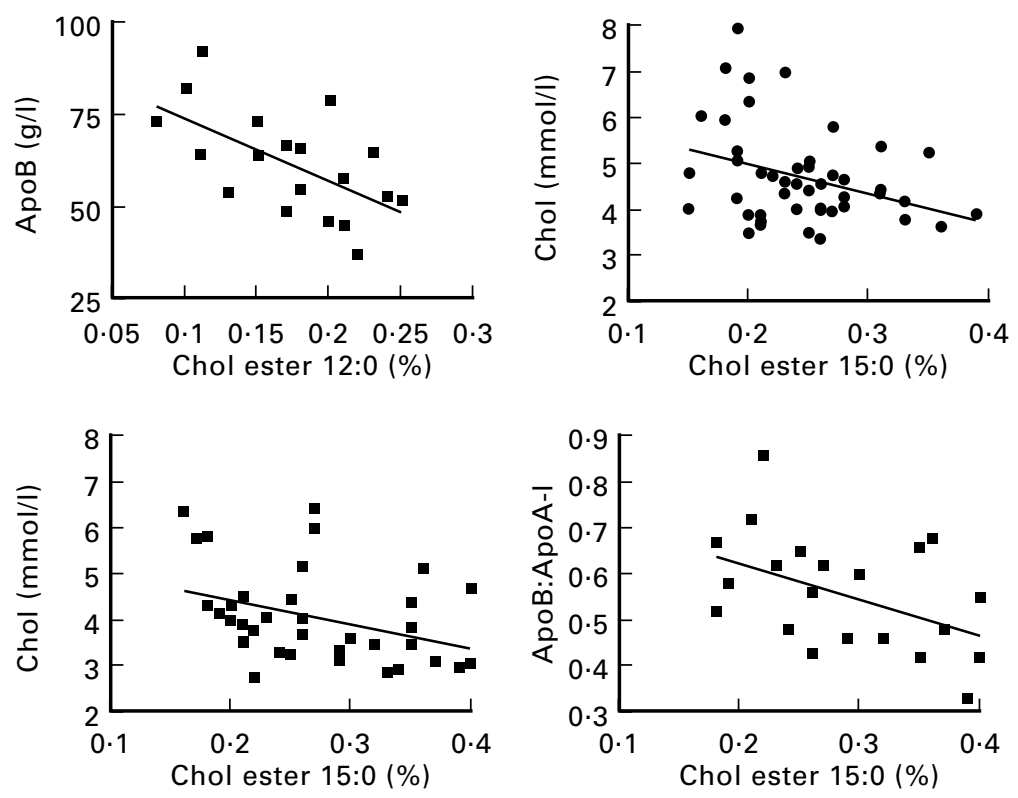

Fig. 1. Scatter plots showing the relationships between the proportions of certain saturated fatty acids in the serum cholesterol esters and the concentrations of cholesterol (Chol) and apolipoproteins (Apo) in serum. $\mathbf{\square}$, boys, $\bullet$, girls. For details of analytical procedures see p. 334. Chol ester 12:0 v. ApoB, boys $r-0.61 P<$ 0.01; Chol ester 15:0 v. Chol, girls $r-0.32, P<0.05$; Chol ester 15:0 v. Chol, boys $r-0.34, P<0.05$; Chol ester v. ApoB:ApoA-I, boys $r-0.50, P<0.05$.

between the different food groups and ApoB, ApoA-I and insulin. There was a negative correlation between the serum cholesterol levels and the intake of juice $(r-0 \cdot 37$, $P<0.05)$ and between the intake of vegetables and serum triacylglycerol $(r-0.32, P<0 \cdot 05)$. Among the boys there were a few strong associations with an inverse association between the serum ApoB concentrations and the estimated intake of vegetables $(r-0.63, P<0.01)$ and a positive relationship with insulin. A similar pattern was seen for the intake of fruit and berries.
There were no significant relationships between the total amount of dairy products in the diet and the metabolic variables among the girls, while the intake of cheese was negatively associated with the serum cholesterol levels $(r$ $-0.35, P<0.05)$ and the triacylglycerol $(r-0.38, P<$ 0.05 ) among the boys. However, when the analysis was restricted to milk fat, as represented by the energy-adjusted intakes of the sum of 4:0-10:0 and 14:0 from dairy products, a pattern emerged which was very similar to that seen in Tables 5 and 6 , with significant negative

Table 5. Relationships between serum cholesterol ester fatty acid composition (\%) and metabolic variables in fifty-one girls and forty-two boysł (correlation coefficients)

\begin{tabular}{|c|c|c|c|c|c|c|c|c|c|c|c|c|}
\hline \multirow{2}{*}{$\begin{array}{l}\text { Serum cholesterol } \\
\text { ester fatty acid }\end{array}$} & \multicolumn{2}{|c|}{ Serum triacylglycerol } & \multicolumn{2}{|c|}{ Serum cholesterol } & \multicolumn{2}{|c|}{ Serum insulin } & \multicolumn{2}{|c|}{ Serum ApoA-III } & \multicolumn{2}{|c|}{ Serum ApoBף } & \multicolumn{2}{|c|}{ Serum ApoB:ApoA-I|| } \\
\hline & Girls & Boys & Girls & Boys & Girls & Boys & Girls & Boys & Girls & Boys & Girls & Boys \\
\hline $\begin{array}{l}12: 0 \\
14: 0\end{array}$ & $+0.47^{\star \star \star}$ & & $-0.34^{\star}$ & $-0.53^{\star *}$ & & & $-0.39 \dagger$ & $-0.48^{*}$ & & $-0.61^{* \star}$ & & \\
\hline $\begin{array}{l}15: 0 \\
16: 0\end{array}$ & & & $-0.32^{\star}$ & $-0.34^{\star}$ & & & $-0.55^{\star \star}$ & & & $-0.43^{\star}$ & & $\begin{array}{l}-0.50^{*} \\
+0.43 \dagger\end{array}$ \\
\hline $\begin{array}{l}16: 1 n-7 \\
18: 0 \\
18: 1 n-9\end{array}$ & $+0.30^{\star}$ & & & & & & & & & $+0 \cdot 64^{\star *}$ & & $+0 \cdot 45^{\star}$ \\
\hline $\begin{array}{l}18: 2 n-6 \\
18: 3 n-6 \\
18: 3 n-3\end{array}$ & $+0.42^{*}$ & & & $+0.60^{\star * \star}$ & & & & & & $\begin{array}{l}-0.51^{*} \\
+0.49^{*}\end{array}$ & & $-0.52^{*}$ \\
\hline $\begin{array}{l}20: 3 n-6 \\
20: 4 n-6 \\
20: 5 n-3 \\
22: 6 n-3\end{array}$ & & & & $\begin{array}{l}+0.36^{*} \\
+0.39^{*}\end{array}$ & $\begin{array}{l}-0.44^{\star \star} \\
-0.45^{\star \star}\end{array}$ & & & & & $\begin{array}{l}+0.63^{\star \star} \\
+0.45^{\star}\end{array}$ & & $+0 \cdot 73^{\star \star \star}$ \\
\hline
\end{tabular}

Apo, apolipoprotein.

${ }^{\star} P<0.05,{ }^{\star *} P<0.01,{ }^{\star \star \star} P<0.001, \dagger P<0.1$

$\ddagger$ For details of analytical procedures see p. 334. All data are adjusted by partial correlation for differences in BMI

|| Girls $n 27$, boys $n 22$.

१ Girls $n 28$, boys $n 22$. 
Table 6. Relationships between dietary fat intake (\% energy) and metabolic variables in forty-two girls and fifty-one boysł (correlation coefficients)

\begin{tabular}{|c|c|c|c|c|c|c|c|c|c|c|c|c|}
\hline \multirow[b]{2}{*}{ Dietary fatty acids } & \multicolumn{2}{|c|}{ Serum triacylglycerol } & \multicolumn{2}{|c|}{ Serum cholesterol } & \multicolumn{2}{|c|}{ Serum insulin } & \multicolumn{2}{|c|}{ Serum ApoA-II| } & \multicolumn{2}{|c|}{ Serum ApoBף } & \multicolumn{2}{|c|}{ Serum ApoB:ApoA-I|| } \\
\hline & Girls & Boys & Girls & Boys & Girls & Boys & Girls & Boys & Girls & Boys & Girls & Boys \\
\hline $4: 0-10: 0$ & & $-0.36^{\star}$ & $-0.32^{*}$ & & & $-0.43^{\star}$ & & & $-0.42^{*}$ & $-0.40 \dagger$ & & \\
\hline $12: 0$ & & & $-0.31^{*}$ & & & & & & $-0.42^{*}$ & $-0.55^{\star *}$ & & $-0.64^{\star \star}$ \\
\hline $14: 0$ & & $-0.41^{\star}$ & $-0.30^{*}$ & & & $-0.47^{\star \star}$ & & & $-0.40^{\star}$ & $-0.40 \dagger$ & & \\
\hline 16:0 & & $-0.50^{\star *}$ & & & & $-0.42^{*}$ & & & & & & \\
\hline $16: 1 n-7$ & $-0.32^{*}$ & & & & & & & & & & & \\
\hline 18:0 & & $-0.35^{\star}$ & & & & & & & & & & $-0.41 \dagger$ \\
\hline $18: 1 n-9$ & & & & & & & & & & & & \\
\hline $18: 2 n-6$ & & & & & & & & & & & & \\
\hline $18: 3 n-3$ & & & & & & & & & & & & \\
\hline $20: 4 n-6$ & $-0.42^{\star *}$ & & & $+0 \cdot 38^{\star}$ & & & & & & & & \\
\hline $20: 5 n-3$ & $+0 \cdot 29^{*}$ & & $+0.33^{*}$ & $+0.48^{\star *}$ & & & & $+0.57^{* *}$ & $+0.49^{\star *}$ & $+0.46^{*}$ & $0.38 \dagger$ & \\
\hline $22: 5 n-3$ & & & & $+0 \cdot 35^{\star}$ & & & & & & $+0.42 \dagger$ & & \\
\hline $22: 6 n-3$ & & & $+0.34^{*}$ & $+0.59^{\star \star *}$ & & & & $+0.44^{*}$ & $+0.41^{*}$ & $+0.48^{*}$ & & \\
\hline
\end{tabular}

Apo, apolipoprotein.

${ }^{\star} P<0.05,{ }^{\star \star} P<0.01,{ }^{\star \star \star} P<0.001, \dagger P<0.1$.

‡ Nutrient intake measured with a 7 d weighed food record and analysed using the Swedish National Food Administration (report no. 14, Pc version, 1992; Uppsala, Sweden). For details of analytical procedures see p. 334. All data are adjusted by partial correlation for differences in BMI.

$\|$ Girls $n 27$, boys $n 22$.

ๆ Girls $n 28$, boys $n 22$

associations in both sexes to the ApoB levels and with similar tendencies for cholesterol (boys and girls) and insulin (girls).

The relationships between the intake of dietary fatty acids, and the fatty acid composition of the serum cholesterol esters respectively, and the clinical variables were reanalysed and adjusted for the intakes of vegetables and juice respectively, in girls as well as boys. The associations shown in Tables 5 and 6 remained virtually unchanged even after these adjustments.

\section{Discussion}

\section{Dietary fat and serum lipids}

The mean intake of saturated fat in different populations is directly related to the serum cholesterol concentrations and to the mortality in CHD (Keys et al. 1986). It has been suggested that a high intake of milk and butter fat may significantly contribute to this relationship (Artauld-Wild et al. 1993). In contrast, when studied within populations (Ascherio \& Willett, 1995; Pietinen et al. 1997) it has not always been possible to demonstrate significant relationships between intake of saturated fat or fatty acids and the incidence of CHD. Similarly, it has been difficult to show significant correlations between dietary fat intake and serum lipid levels in observational studies within populations (Jacobs et al. 1979), in spite of the clear relationships between intake of saturated fatty acids and serum cholesterol and ApoB concentrations seen in a number of controlled intervention studies (Katan et al. 1995). There may be several reasons for this, e.g. insufficient precision of the methods for dietary surveys, large intraindividual day-to-day variations in food intake, genetic variants with high and low responders to the effects of dietary fat, or a small and heterogenous sample with regard to age and sex. Another possibility is that the relationships between dietary fat intake and serum lipid levels are more complex than has been realised hitherto.
Our subjects were recruited from, and well representative of, a carefully characterized population of adolescents, where the possible confounding effects of age and sex were eliminated. A well established, validated method for the dietary survey was used (weighed $7 \mathrm{~d}$ records). This may have facilitated the demonstration of several significant, and surprisingly strong, correlations between dietary fatty acids (Table 6, Fig. 2) and the serum cholesterol ester fatty acid composition (Table 5, Fig. 1) on the one hand and metabolic variables on the other. The dietary fat intake, as estimated from the dietary records, shows that a relatively low proportion of the energy is derived from fat (Table 2) with a rather low content of cholesterol. This is well in accordance with the dietary intake calculated for the whole group (Samuelson et al. 1996) and closely similar to that reported earlier from a study of 14- and 17-year-old boys and girls in northern Sweden (Bergström et al. 1995). The fatty acid patterns in the serum cholesterol esters (Table 3) were similar in boys and girls, as also shown earlier in Finnish children (Moilanen et al. 1986).

The dominating source of saturated fatty acids with chain lengths of four to ten, twelve and fourteen $\mathrm{C}$ atoms in the diet is milk fat (Gunstone et al. 1994). More than two-thirds of the short-chain fatty acids (four to ten $\mathrm{C}$ atoms) in the present study were derived from dairy fat among both boys and girls. This was also true for 50-60\% of the lauric (12:0) and myristic (14:0) acids while only approximately one-third of the palmitic (16:0) and palmitoleic $(16: 1)$ acids in the diet were derived from dairy fat. A larger proportion of the latter fatty acids, than of the saturated fatty acids with a shorter chain length, was derived from meat and meat products.

\section{Serum fatty acid composition, fat intake and metabolic variables}

Surprisingly, there were generally negative associations between the proportions of saturated fatty acids with chain 


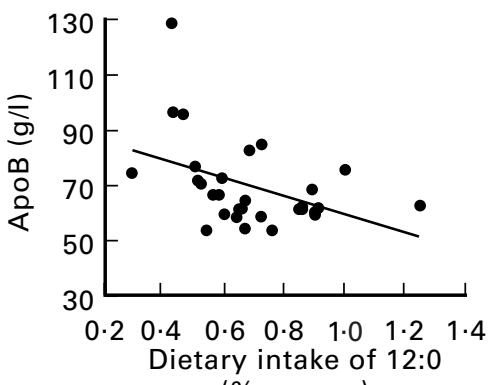

(\% energy)

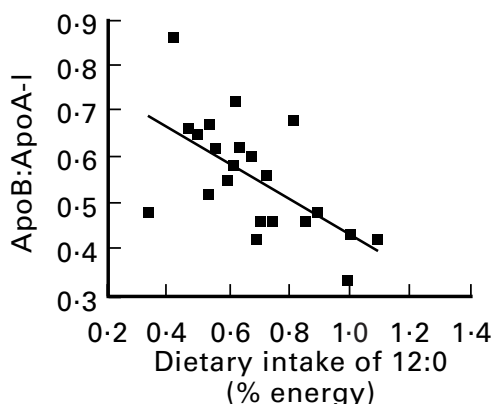

Fig. 2. Scatter plots showing the relationships between the proportion of lauric acid $(12: 0)$ in the diet and the concentrations of apolipoproteins (Apo) in serum. $\mathbf{\square}$, Boys; -, girls. For details of analytical procedures see p. 334. Nutrient intake was measured with a $7 \mathrm{~d}$ weighed record and analysed using the Swedish National Food Administration food database (report no. 14, Pc Version, 1992; Uppsala, Sweden). Dietary intake of 12:0 v. ApoB: girls $r-0.42, P<0.05$; boys $r-0.55 P<0.01$. Dietary intake of 12:0 v. ApoB:ApoA-I: boys $r-0.64, P<0.01$. lengths up to fifteen $\mathrm{C}$ atoms in the serum cholesterol esters (Table 5, Fig. 1) and in the diet (Table 6, Fig. 2), and the serum cholesterol and ApoB concentrations respectively. Few studies have earlier addressed this question. Moilanen et al. (1986) reported a positive, although rather weak, correlation between 14:0 in the serum cholesterol esters and the serum cholesterol and ApoB concentrations in Finnish children but did not analyse 12:0 or 15:0. In three large studies of the associations between dietary variables and plasma lipids and lipoproteins in the Lipid Research Clinics populations (Glueck et al. 1982; Gordon et al. 1982; Schwartz et al. 1982) very weak correlations were found between serum lipid levels and dietary fats, and no effort was made to separate the different saturated fatty acids in the diet. The relationships between the proportions of palmitoleic and linoleic acids in serum and ApoB (Table 5), and the positive relationships between the long-chain $n-6$ and $n-3$ fatty acids and the concentrations of serum cholesterol and serum ApoB (Table 5 and 6) are essentially in accordance with earlier findings (Moilanen, 1986).

The data presented here refer to correlations between the relative content of fatty acids in the diet and in the serum cholesterol esters and metabolic variables. Very similar results were seen when the absolute intake of fatty acids in the diet was used in the calculations, as well as when the analyses were done without adjustment for differences in BMI. In addition, adjustment for different degrees of physical activity did not change the main results.

The negative relationships between the content of saturated fatty acids with a chain length of less than sixteen $\mathrm{C}$ atoms in the diet and serum, and the serum ApoB and cholesterol concentrations could be a chance finding. Although not possible to rule out, this does not seem very likely. The relationships were seen independently in girls as well as in boys. Similarly, rather strong correlations were seen in relation to both estimated intake of milk fat, to the intake of specific saturated fatty acids, and to the proportions of the corresponding fatty acids in serum.

It is well documented that the saturated fatty acids with twelve, fourteen and sixteen $\mathrm{C}$ atoms elevate the serum cholesterol concentrations when administered in the diet during controlled experiments (Katan et al. 1995). In accordance with this, positive relationships between the estimated intake of these fatty acids, or the proportions in serum, and the serum cholesterol and ApoB concentration would have been expected. The major source of saturated fatty acids in the diet with four to fourteen $\mathrm{C}$ atoms is milk fat. The proportions of 15:0 in serum cholesterol esters are directly associated with the estimated dairy fat intake (Smedman et al. 1999) and 15:0 in adipose tissue has been shown to be a surprisingly good marker for dietary intake of milk fat (Wolk et al. 1998).

It is conceivable that a high intake of dairy fat may be a part of a 'healthy food pattern' where other dietary factors counterbalance the expected associations between the saturated fat intake and lipid levels or that the correlations are due to some other characteristics of the food intake. To exclude the possibility that the relationships shown in Tables 5 and 6 were confounded by certain dietary patterns, we adjusted by ANOVA for the intake of certain food groups that in univariate analysis were significantly related to the variables studied, and repeated the analyses with 
virtually unchanged results. The relationships between the total intake of dairy products and the metabolic variables were rather weak with the exception of a significant inverse relationship between intake of cheese and the serum cholesterol levels among the boys. However, when the fatty acids 4:0-10:0 and 14:0 in dairy products were chosen as markers for intake of milk fat, similar associations were seen as earlier supporting the idea that the relationships shown might (directly or indirectly) be associated with the intake of milk fat. Inverse relationships were also seen between the estimated intake of milk fat in elderly men and clinical variables such as BMI, waist circumference and LDL:HDL ratio (Smedman et al. 1999).

There is a possibility that dairy fat contains some component, in addition to the saturated fatty acids, which may have other effects on the serum lipoprotein pattern when supplied in the diet during long time periods. Thus, it has recently been suggested that conjugated linoleic acid, which is found in fat from ruminants, may have antiatherogenic and serum lipid lowering effects in rabbits (Lee et al. 1994) and in hamsters (Van Amelsvoort \& Meijer, 1997).

It was earlier shown that a high intake of saturated fatty acids and a low intake of linoleic acid, or a low proportion of linoleic acid in the serum cholesterol esters, usually coincides with a relatively high proportion of the longchain $n-6$ derivatives in serum, and also with long-chain unsaturated fatty acids of the $n-3$ series (Laserre et al. 1985). There is a competition between the $n-6$ and $n-3$ series for the desaturase and elongase enzymes (Siguel \& Maclure, 1987). If the diet contains a high proportion of saturated fatty acids, and a low proportion of linoleic acid, the conversion of both linoleic acid and $\alpha$-linolenic acid to long-chain unsaturated metabolites is increased. This may explain the positive relationships between serum cholesterol and ApoB on the one hand and the long-chain, unsaturated fatty acids on the other in this study. As linoleic acid comprises about $50 \%$ total cholesterol ester fatty acids, an apparent reciprocal effect of linoleic acid and the long chain, unsaturated fatty acids on serum cholesterol, as judged from the proportions of fatty acids in serum, may also be due to some extent to passive redistribution of the less abundant fatty acids secondary to changes in linoleic acid proportions. This cannot, however, explain the associations between the dietary content of long-chain $n-3$ fatty acids and serum cholesterol and ApoB, which is more likely to be due to the well known LDL-elevating effect of $n-3$ fatty acids (Harris, 1997).

\section{Acknowledgements}

Financial support was provided by the Swedish Farmer's Foundation for Agricultural Research, the Swedish Dairy Council and the Swedish Margarine Industrial Association for Nutritional-Physiological Research.

\section{References}

Artauld-Wild SA, Connor SL, Sexton G \& Connor WE (1993) Differences in coronary mortality can be explained by differences in cholesterol and saturated fat intakes in 40 countries but not in France and Finland. Circulation 88, 27712779.

Ascherio A \& Willett WC (1995) New directions in dietary studies of coronary heart disease. Journal of Nutrition 125, Suppl., 647S-655S.

Bergström E, Hernell O \& Persson L-Å (1993) Dietary changes in Swedish adolescents. Acta Paediatrica Scandinavica 82, 472480.

Bergström E, Hernell O, Persson L-Å \& Vessby B (1995) Serum lipid values in adolescents are related to family history, infant feeding and physical growth. Atherosclerosis 117, 1-13.

Bingham SA (1987) The dietary assessment of individuals; methods, accuracy, new techniques and recommendations. Nutrition Abstracts Review (Series A) 57, 705-742.

Boberg M, Croon L-B, Gustafsson I-B \& Vessby B (1985) Platelet fatty acid composition relation to fatty acid composition in plasma and to serum lipoprotein lipids in healthy subjects with special reference to the linoleic acid pathway. Clinical Science 68, 581-587.

Bratteby LE, Sandhagen B, Fan H, Enghardt H \& Samuelson G (1998) Total energy expenditure and physical activity as assessed by the doubly labelled water method in Swedish adolescents in whom energy intake was underestimated by 7-d dietary records. American Journal of Clinical Nutrition 67, 905-911.

Bratteby LE, Sandhagen B, Fan H \& Samuelson G (1997a) A 7 day activity diary for assessment of daily energy expenditure validated by the doubly labelled water method in adolescents. European Journal of Clinical Nutrition 51, 592-600.

Bratteby LE, Sandhagen B, Lötborn M \& Samuelson G (1997b) Daily energy expenditure and physical activity assessed by an activity diary in 386 randomly selected 15 -year-old adolescents. European Journal of Clinical Nutrition 51, 585-591.

Da Col P \& Kostner GM (1983) Immunoquantification of total apolipoprotein B in serum by nephelometry: influence of lipase treatment and detergents. Clinical Chemistry 29, 1045-1050.

Field CJ, Angel A \& Clandinin MT (1985) Relationship of diet to the fatty acid composition of human adipose tissue structural and stored lipids. American Journal of Clinical Nutrition 42, $1206-1220$.

Glatz FCG, Soffers AEM \& Katan MB (1989) Fatty acid composition of serum cholesteryl esters and erythrocyte membranes as indicators of linoleic acid intake in man. American Journal of Clinical Nutrition 49, 269-276.

Glueck CJ, Waldman G, McClish DK, Morrison JM, Khoury P, Larsen R, Salz K, Rifkind BM \& Mattson FH (1982) Relationships of nutrient intake to lipids and lipoproteins in 1234 white children. The Lipid Research Clinics Prevalence Study. Arteriosclerosis 2, 523-536.

Gordon T, Fisher M, Ernst N \& Rifkind BM (1982) Relation of diet to LDL cholesterol, VLDL cholesterol, and plasma total cholesterol and triglycerides in white adults. The Lipid Research Clinics Prevalence Study. Arteriosclerosis 2, 502512.

Gunstone FD, Harwood JL \& Padley FP (1994) Occurrence and characteristics of oils and fats. In The Lipid Handbook, pp. 47224 [FP Padley, FD Gunstone and JL Harwood, editors]. Cambridge: The University Press.

Håglin L, Hagman U \& Nilsson M (1995) Evaluation of the "Matmallen". A means of estimating consumed amounts of food. Scandinavian Journal of Nutrition 39, 79-83.

Harris WS (1997) N-3 fatty acids and serum lipoproteins: human studies. American Journal of Clinical Nutrition 65, S1645S1654.

Jacobs DR Jr, Anderson DT \& Blackburn H (1979) Diet and serum cholesterol - Do zero correlations negate the relationship? American Journal of Epidemiology 110, 77-88. 
Katan MB, Zock PL \& Mensink RP (1995) Dietary oils, serum lipoproteins, and coronary heart disease. American Journal of Clinical Nutrition 61, Suppl., 1368S-1373S.

Keys A, Menotti A, Karvonen MJ, Aravanis C, Blackburn H, Buzina R, Djordjevic BS, Dontas AS, Fidanza F, Keys MH et al. (1986) The diet and 15-year death rate in Seven Countries study. American Journal of Epidemiology 124, 903-915.

Laserre M, Mendy F, Spielmann D \& Jacotot B (1985) Effects of different dietary intake of essential fatty acids on C 20:3n-6 and C 20:4n-6 serum levels in human adults. Lipids 20, 227-233.

Lee KN, Kritchevsky D \& Pariza MW (1994) Conjugated linoleic acid and atherosclerosis in rabbits. Atherosclerosis 108, 19-25.

Ma J, Folsom AR, Shahar E \& Eckfelt JH (1995) Plasma fatty acid composition as an indicator of habitual dietary fat intake in middle-aged adults. American Journal of Clinical Nutrition 62 , 264-271.

Moilanen T, Solakivi-Jaakkola T, Viikari J, Räsänen L, Åkerblom HK, Uhari M, Pasanen M \& Nikkari T (1986) Fatty acid composition of serum cholesteryl esters in relation to serum lipids and apolipoproteins in 3-18-year-old Finnish children and adolescents. Atherosclerosis 59, 113-119.

Nikkari T, Lukkainen P, Pietinen P \& Puska P (1995) Fatty acid composition of serum lipid fractions in relation to gender and quality of dietary fat. Annals of Medicine 27, 491-498.

Pietinen P, Ascherio A, Korhonen P, Hartman AM, Willett WC, Albanes D \& Virtamo J (1997) Intake of fatty acids and risk of coronary heart disease in a cohort of Finnish men. The alphatocopherol, beta-carotene cancer prevention study. American Journal of Epidemiology 145, 876-887.

Samuelson G, Bratteby LE, Enghardt H \& Hedgren M (1996) Food habits and energy and nutrient intake in Swedish adolescents approaching the year 2000. Acta Paediatrica 85, Suppl., 415.

Schwartz W, Trost DC, Reiland SL, Rifkind BM \& Heiss G (1982) Correlates of low density lipoprotein cholesterol: Associations with physical, chemical, dietary, and behavioral characteristics. The Lipid Research Clinics Prevalence Study. Arteriosclerosis 2, 513-522.

Siguel EN \& Maclure M (1987) Relative activity of unsaturated fatty acid metabolic pathways in humans. Metabolism 36, 664669.

Smedman A, Gustafsson I-B, Berglund L \& Vessby B (1999) Pentadecanoic acid (15:0) in serum as a marker for intake of milk fat. The relationships between the intake of milk fat and metabolic risk factors. American Journal of Clinical Nutrition 69, 22-29.

Tanner JM (1962) Growth at Adolescence. 2nd ed. Oxford: Blackwell.

Wolk A, Vessby B, Ljung H \& Barrefors P (1998) Evaluation of a biologic marker for dairy fat intake. American Journal of Clinical Nutrition 68, 291-295.

Van Amelsvoort JMM \& Meijer GW (1997) The effect of conjugated linoleic acid in dietary triglycerides on atherosclerotic risk factors in the hamster. Atherosclerosis 134, 335 (Abstract).

Van Staveren WA, Deurenberg P, Katan MB, Burema J, de Groot LC \& Hoffmans MD (1986) Validity of the fatty acid composition of subcutaneous fat tissue microbiopsies as an estimate of long-term average fatty acid composition of the diet of separate individuals. American Journal of Epidemiology 123, 455-463. 